\title{
A Novel Approach for Sustainable Supplier Selection Using Differential Evolution: A Case on Pulp and Paper Industry
}

\author{
Sunil Kumar Jauhar ${ }^{1}$, Millie Pant ${ }^{1}$, and Ajith Abraham ${ }^{2}$ \\ ${ }^{1}$ Indian Institute of Technology, Roorkee, India \\ ${ }^{2}$ Machine Intelligence Research Labs (MIR Labs), Scientific Network for Innovation \\ and Research Excellence, Auburn 98071, WA, USA \\ \{suniljauhar.iitr,millidma\}@gamil.com, ajith.abraham@ieee.org
}

\begin{abstract}
Diverse sustainable supplier selection (SSS) methodologies have been suggested by the practitioners in earlier, to find a solution to the SSS problem. A SSS problem fundamentally is a multi-criteria practice. It is a judgment of tactical significance to enterprises. The nature of this decision usually is difficult and unstructured. Optimization practices might be useful tools for these types of decision-making difficulties. During last few years, Differential Evolution has arisen as a dominating tool used for solving a variety of problems arising in numerous fields. In the current study, we present an approach to find a solution to the SSS problem using Differential Evolution in pulp and paper industry. Hence this paper presents a novel approach is to practice Differential Evolution to select the efficient sustainable suppliers providing the maximum fulfillment for the sustainable criteria determined. Finally, an illustrative example on pulp and paper industry validates the application of the present approach.
\end{abstract}

Keywords: Sustainable Supplier Selection, Sustainable Supply Chain Management, Differential Evolution, DEA.

\section{Introduction}

Now days in view of the growing awareness concerning sustainability in business firm, the sustainable supplier selection would be the vital element in the process of managing a sustainable supply chain. Developing an efficient and robust sustainable supply chain (also known as sustainable SCM) is a crucial task for the success of a business firm. One of the most significant factors that help in building a strong sustainable supply chain is the SSS process. It is natural that for a particular product, huge amounts of suppliers/ vendors are available in the market. Now, it is the duty of the purchasing managers to recognize the most suitable clusters of sustainable suppliers for their product. Evaluation plus selection of sustainable suppliers is a complex process and depend on a large number of qualitative as well as quantitative factors to ensure a cost effective model without compromising with the quality. 
Differential evolution (DE) algorithm proposed by Stron and Price in 1995 [1], It is a population set based evolutionary algorithm that has been applied successfully to a wide range of problems $[2,3,4,5,6]$. The motive of this paper is to bring about to SSS approach. In the current research article, DE is used for solving the SSS problem modeled with the help of data envelopment analysis (DEA).

This paper is organized in eight sections. Subsequent to the introduction in Section 1 , the SCM in pulp and paper industry, sustainable supplier selection (SSS) in addition to Problem statement and methodology are briefed in Sections 2, 3 and 4 respectively. Section 5 describes the Mathematical Formulation of the Problem with DEA used in this article. Section 6 describes the DE algorithm for SSS. Finally, a discussion and conclusion with summary drawn from the current research article are given in Section 7 and 8.

\section{$2 \quad$ SCM in Pulp and Paper Industry}

The pulp and paper industry produces a great amount of paper as well as cellulose based fibre products. Bulletin papers, copy papers, different kinds of tissue, bottle sticky label, cigarette papers plus coffee filter are just a small number of patterns of the products frequently used in our daily life. There is a huge amount of activity involved in the chain behind these products; such a system of actions is acknowledged as supply chain in management as well as operation research works [7]. The manufacturing of paper can be separated into six main process areas, which are [8]: (1) Wood preparation (2) Pulping (3) Bleaching (4) Chemical recovery (5) Pulp drying (non-integrated mills only) and (6) Papermaking. Fig. 1 presents a flow diagram of the paper manufacturing process in pulp and paper industry.

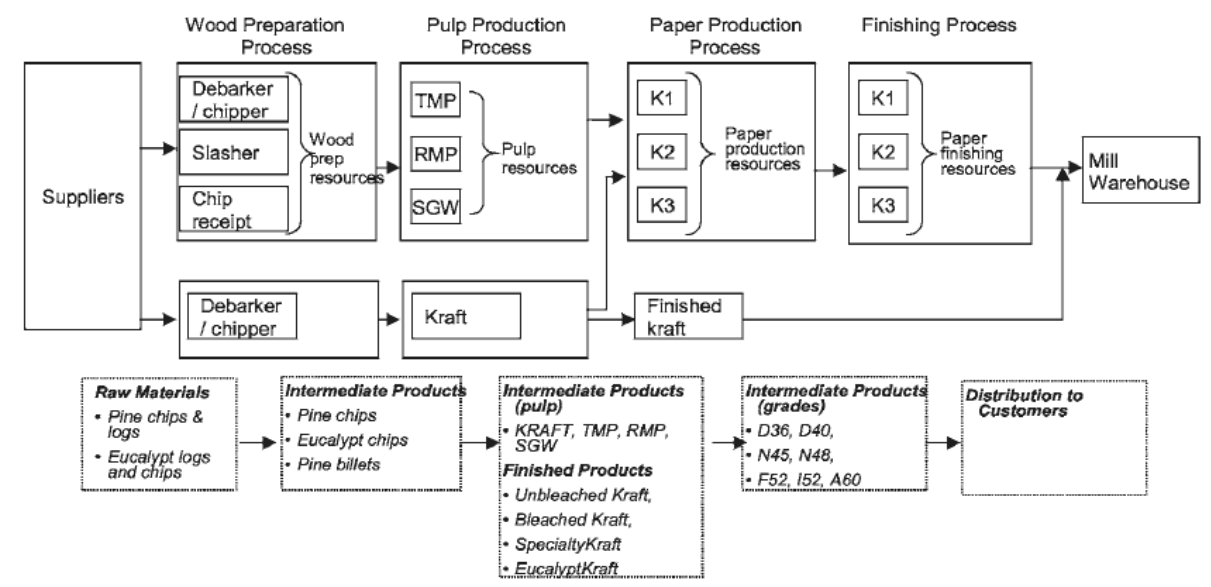

Fig. 1. Paper manufacturing process in pulp and paper industry (Source: [9])

Business organizations are gradually identifying that the effective management of sustainable supply chains is a primary driver of value creation as well as environmental performance. While lots of organizations in the automotive, consumer goods, and electronics industries have exploited the environment concern of SCM, industries in 
the pulp and paper area are just start to identify the immense scope of the potential future prospects that exist. These industries are categorized by a huge and extremely incorporated supply chain. The entire supply chain starts in the procurement network, carry on through production network, distribution network and finishes by sales network. The fig. 2 presents an easy illustration of the pulp and paper industry supply chain organization with corresponding main SCM level.

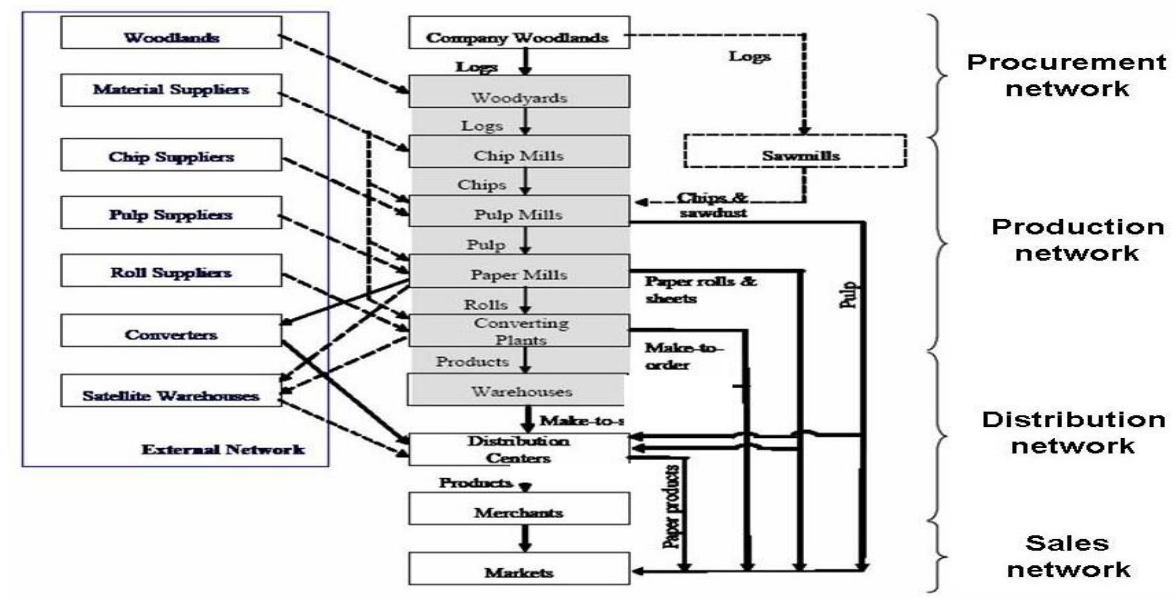

Fig. 2. The pulp and paper supply chain organization. (Source: [10])

\subsection{Pulp and Paper $\mathrm{CO}_{2}$ Emission Sources}

The paper products manufacturing companies has a significant and complicated role in the worldwide carbon cycle. Pulp and paper are massive consumers of energy. In fact, the world's fifth- leading consumers of energy is the pulp and paper industry. The World Resources Institute, a body of experts, placed the industry's $\mathrm{CO}_{2}$ emissions at around 500m tons worldwide in 2005. Rather, European companies are reasonably green. The Confederation of European Paper Industries (CEPI), a trade association, states his associates' emissions were 46m tons in 2011 [9].

Greenhouse gas (GHG) emissions from the pulp and paper source group are most of the part of $\mathrm{CO}_{2}$ with lesser quantity of $\mathrm{CH}_{4}$ as well as $\mathrm{N}_{2} \mathrm{O}$. The GHG emissions allied with the pulp and paper industry's processes can be caused by [10]: (1) The process of burning on-site energies; (2) Non-energy-related emission causes, for example by-product $\mathrm{CO}_{2}$ emissions from the lime kiln chemical reactions and $\mathrm{CH}_{4}$ emissions from wastewater treatment and (3) indirect emissions of GHG are related through the off-site production of steam in addition to electricity that are procured by or pass on to the industry.

Environmental concern over the pulp and paper industry has until recently been concentrated on emissions to air and water from pulping, bleaching, and paper making practices. A blend of strategy tools (usually emission ceilings) has reduced emissions to air as well as water from these industries significantly [11]. In this days and 
age, concern is usually for the sectors effect on external network of pulp and paper supply chain organization (see Fig. 2) and its emissions of $\mathrm{CO}_{2}$.

\section{$3 \quad$ Sustainable Supplier Selection (SSS)}

Supplier selection is a significant portion of supply chain management (SCM). Supplier selection comprises numerous criteria including price, lead time, quality, speed, delivery performance, reliability, etc and often encompasses the choice of one meanwhile give up the other. The supplier selection practices are comprehensively studied in the literature with multi-criteria decision making models. These models comprise such practices, as the AHP, ANP, CBR, DEA, fuzzy set theory, GA, mathematical programming, SMART, and their hybrid variants. Different researchers have studied the works in the past relating the supplier evaluation and selection problem $[12,13,14,15,16,17,18,19,20,21,22,23,24]$.

At the present time, sustainable development has turn out to be a buzzword that acknowledged a lot of attentions in numerous fields like manufacturing [25], business development [26], tourism [27] and agriculture [28]. Also, in SCM both academics and general practitioner contemplate the sustainable concerns in their workings. Sustainable SCM is the managing of resources, informations and capital flows, as well as collaboration between firms alongside the supply chain, meanwhile taking into account the objectives from all three dimensions, such as financial, ecological and societal, of sustainable growth derived from client and investor wants [29]. To select the potential suppliers, two focuses comprising significance one is the degree of the selection criteria, and second one is the suppliers' sustainable performance, these two focuses need to be verified with the appropriate decision makers. Therefore, to manage this problem and cope with the imprecision that is be found in the SSS problem, use of Differential evolution (DE) algorithm is explored in this article.

\section{$4 \quad$ Problem Statement and Methodology}

The case study presented in this paper stands a hypothetical paper manufacturer in India (X Company). After verifying a group of criteria in a view point of sustainable merits, some criteria including lead time, quality, price, service quality and $\mathrm{CO}_{2}$ emissions of the delivered products are derived for SSS problem.

In current study we split the criteria in two manners: the input and output criteria. The input criteria are the traditional supplier selection criteria, such as lead time, price and quality of the delivered goods. The output criteria are the service quality and $\mathrm{CO}_{2}$ emission of the product and services. We assume that the service quality and $\mathrm{CO}_{2}$ emission are the output of the examined model. The data is shown in Table I with the supplier's database covering input as well as output criteria of an item provided in the shipment of pulp and paper industry.

In this study, a supplier is considered efficient if the efficiency score is 1 otherwise it is considered as inefficient. Data for Service quality of items is taken from concept of Service quality dimension based on 12 questionnaires including 27 questions given 
by [30] and for $\mathrm{CO}_{2}$ Emissions, LOCOG Guidelines on Carbon Emissions of Products and Services -Version 1 [31] is considered.

\subsection{Methodology}

To measure and analyze the relative efficiency of 18 suppliers, we follow a four step methodology:

$>$ Design a criteria containing input and output criteria

$>$ Select a problem

$>$ Formulate the mathematical model of the SSS problem with the help of DEA.

$>$ Apply DE on mathematical model.

The present model can be carry out for any quantity of suppliers and there is no limitation, by using this model, the company can obtain a recommended combination of efficient suppliers.

Table 1. Data for numerical example

\begin{tabular}{|c|c|c|c|c|c|}
\hline \multirow{2}{*}{ Criteria } & \multicolumn{4}{l}{ Inputs } & \multicolumn{2}{l|}{ Output } \\
\cline { 2 - 6 } & $\begin{array}{l}\text { Lead time } \\
\text { (L) (Day) }\end{array}$ & $\begin{array}{c}\text { Quality(Q) } \\
\text { \% }\end{array}$ & $\begin{array}{c}\text { Price (P) } \\
\text { (Rs.) }\end{array}$ & $\begin{array}{l}\text { Service quali- } \\
\text { ty (SQ) }\end{array}$ & $\begin{array}{l}\mathbf{C O}_{2} \text { Emis- } \\
\text { sion } \\
\text { (CE) }\end{array}$ \\
\hline 1 & 3 & 75 & 187 & 84 & 40 \\
\hline 2 & 2 & 77 & 195 & 76 & 30 \\
\hline 3 & 4 & 85 & 272 & 27 & 25 \\
\hline 4 & 5 & 86 & 236 & 110 & 22 \\
\hline 5 & 3 & 74 & 287 & 94 & 38 \\
\hline 6 & 6 & 62 & 242 & 102 & 10 \\
\hline 7 & 3 & 73 & 168 & 82 & 24 \\
\hline 8 & 4 & 92 & 396 & 63 & 38 \\
\hline 9 & 2 & 77 & 144 & 55 & 26 \\
\hline 10 & 3 & 69 & 137 & 61 & 18 \\
\hline 11 & 6 & 54 & 142 & 122 & 24 \\
\hline 12 & 5 & 57 & 196 & 75 & 30 \\
\hline 13 & 1 & 77 & 247 & 80 & 55 \\
\hline 14 & 3 & 61 & 148 & 121 & 39 \\
\hline 15 & 4 & 69 & 294 & 125 & 8 \\
\hline 16 & 6 & 94 & 249 & 76 & 6 \\
\hline 17 & 2 & 88 & 121 & 114 & 55 \\
\hline 18 & 1 & 78 & 269 & 65 & 48 \\
\hline
\end{tabular}

\section{Mathematical Formulation of the Problem with DEA}

DEA based method is used for determining the efficiencies of Decision-Making Units (DMUs) on the basis of multiple inputs and outputs [32]. DMU can comprise of business firms, divisions of huge groups such as institution of higher education, schools, hospitals, power plants, police stations, tax offices, prisons, a set 
of organizations etc. [33,34,35,36]. The DMU well-describe in this research work using input as well as output criteria are as follows:

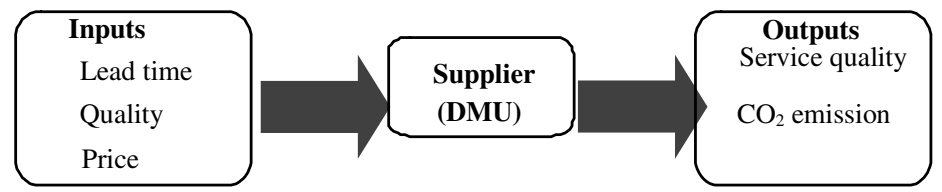

The performance of DMU is estimated in DEA by the concept of efficiency or productivity, which the proportion of weights sum of outputs $(\mathrm{o} / \mathrm{p})$ to the weights sum of (i/p) inputs [37] i.e

$$
\text { Efficiency }=\frac{\text { Weighted sum of } \mathrm{O} / \mathrm{P}}{\text { Weighted sum of } \mathrm{I} / \mathrm{P}}
$$

The two basic DEA models are the CCR (Charnes, Cooper and Rhodes) model [38] and the BCC (Banker, Charnes and Cooper) model [39], these two models distinguish on the returns to scale assumed. The former assumes constant returns-toscale whereas the latter assumes variable returns-to-scale [32]. In the current study we use CCR model which is well-defined further down:

Suppose that there are $N$ DMUs and each unit have $I$ input and $O$ outputs then the efficiency of $m^{\text {th }}$ unit is achieved by resolving the below model which is presented by Charnes et al [38].

$$
\begin{aligned}
& \operatorname{Max} E_{m}= \frac{\sum_{k=1}^{O} w_{k} \text { Output }_{k, m}}{\sum_{l=1}^{i} z_{l} \text { Input }_{l, m}} \\
& \mathbf{O} \leq \frac{\sum_{k=1}^{0} w_{k} \text { Output }_{k, n}}{\sum_{l=1}^{i} z_{l} \text { Input }_{l, n}} \leq 1 ; n=1,2 \ldots, m . . N \\
& w_{k}, z_{l} \geq 0 ; \forall k, l
\end{aligned}
$$

Where

$E_{m}$ is the efficiency of the $m^{\text {th }}$ DMU, $k=1$ to $O, l=1$ to $I$ and $n=1$ to $N$.

Output $_{k, m}$ is the $k^{\text {th }}$ output of the $m^{\text {th }}$ DMU and $w_{k}$ is weight of output Output $_{k, m}$

Input $t_{l, m}$ is the $l^{\text {th }}$ input of $m^{\text {th }}$ DMU and $z_{l}$ is the weight of Input $t_{l, m}$

output $_{k, n}$ and input $l_{l, n}$ are the $k^{\text {th }}$ output and $l^{\text {th }}$ input respectively of the $n^{\text {th }}$ DMU, Where $n=1$, 2 ...m...N

The fractional program shown in Equ-2 can be converted in a linear program which is shown in Equ-3.

$$
\begin{aligned}
& \operatorname{Max} E_{m} \sum_{k=1}^{O} w_{k} \text { Output }_{k, m} \\
& \text { s.t. } \\
& \sum_{l=1}^{I} z_{l} \text { Input }_{l, m}=1 . \\
& \sum_{k=1}^{O} w_{k} \text { Output }_{k, n}-\sum_{l=1}^{I} z_{l} \text { Input }_{l, n} \leq 0, \quad \forall n \\
& w_{k}, z_{l} \geq 0 ; \quad \forall k, l
\end{aligned}
$$


To calculate the efficiency score for each DMU we run the above program run $N$ times. A DMU is considered efficient if the efficiency score is 1 otherwise it is considered as inefficient.

\subsection{Mathematical Model}

Based on the hypothetical statistics stated in Table I the DEA model of $K^{\text {th }}$ DMU will be as follows:

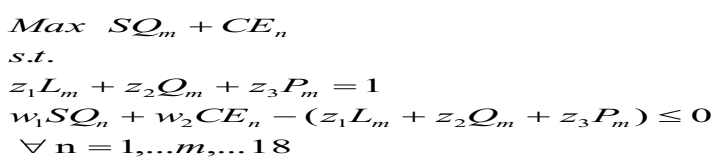

\section{DE Algorithm}

Differential evolution (DE) algorithm proposed by Stron and Price in 1995 [1], It is a type of evolutionary algorithm, used to most effective use of (optimize) the functions. It is a population set based evolutionary algorithm for global optimization. In current study we have used DE/rand/1/bin scheme and DE algorithm from reference [1].

\subsection{Pseudo Code for the DE Algorithm}

Table 2. The Pseudo code for the DE algorithm

\begin{tabular}{|c|c|}
\hline 1 & Begin \\
\hline 2 & $\begin{array}{l}\text { Generate uniformly distribution random population } P=\left\{X_{l, G}, X_{2, G}, \ldots, X_{N P, G}\right\} \text {. } \\
X_{i, G}=X_{\text {lower }}+\left(X_{\text {upper }}-X_{\text {lower }}\right) * \operatorname{rand}(0,1) \text {, where } i=1,2, \ldots, N P\end{array}$ \\
\hline 3 & Evaluate $f\left(X_{i, G}\right)$ \\
\hline 4 & While (Termination criteria is met ) \\
\hline 5 & \{ \\
\hline 6 & For $i=1: N P$ \\
\hline 7 & \{ \\
\hline 8 & Select three random vector $\mathrm{X}_{r l, G}, \mathrm{X}_{r 2, G}, \mathrm{X}_{r 3, G}$ where $i \neq r_{1} \neq r_{2} \neq r_{3}$ \\
\hline 9 & Perform mutation operation \\
\hline 10 & Perform crossover operation \\
\hline 11 & Evaluate $f\left(U_{i, G}\right)$ \\
\hline 12 & Select fittest vector from $X_{i, G}$ and $U_{i, G}$ to the population of next generation \\
\hline 13 & \} \\
\hline 14 & Generate new population $Q=\left\{X_{l, G+1}, X_{2, G+1}, \ldots, X_{N P, G+1}\right\}$ \\
\hline 15 & \}/* end while loop*/ \\
\hline 16 & END \\
\hline
\end{tabular}




\subsection{Constraints Handling}

For the constraint problems various methods have been suggested in literature. A survey of different methods for constraint handling can be found in [40] and [41]. In this paper Pareto-Ranking method is used for handling the constraints [42].

\subsection{Parameter Setting for the DE Algorithm}

In present research article we have applied DE to solve the DEA based mathematical model. The parameter settings for DE are given in Table-3.

Table 3. Parameter setting for DE

\begin{tabular}{ll}
\hline Pop size $(\mathrm{NP})$ & 100 \\
Scale Factor (F) & 0.5 \\
Crossover rate $(\mathrm{Cr})$ & 0.9 \\
Max iteration & 3000
\end{tabular}

The program is implemented is DEV C++ and all the uniform random number is generated using the inbuilt function rand ( ) in DEV C++. The fitness value is taken as the average fitness value in 30 runs and the program is terminate when reach to Max-Iteration. A buyer (decision maker) can effect an assessment (supplier evaluation) with the ability to choose of weight system. For this purpose with the help of program which is implemented is DEV C++, we intended to generate all the uniform random number (in between 0 to 1) using the inbuilt function rand () in DEV C++, to assist the selection of the weights for input as well as output criteria in a manner to permit the control of the result for the sustainable supplier evaluation and assessment practice.

\section{$7 \quad$ Results and Discussions}

In the Table-4 results of all DMUs are given. From this Table we can see that the research of efficient SSS practice can acquire a desirable cluster of competent sustainable suppliers 11, 14 and 17 using DE algorithm gives the better solution.

For the current research conducted in 18 suppliers, the results are:

1. Suppliers 11, 14 and 17, the efficiency score is 1 so these suppliers are assumed to be $100 \%$ sustainable efficient.

2. Supplier 3 is probably the most inefficient in comparison to all other suppliers.

3. Suppliers 11, 14 and 17 would be the most suitable set of suppliers (or key suppliers).

4. By using this DE algorithm, the business firms can acquire a desirable clusters of competent sustainable suppliers. 
5. Combination of suppliers 11,14 and 17 would be the desirable clusters of competent sustainable suppliers set meanwhile the business firms requiring single-item sustainable suppliers.

In the Table-5 results of all DMUs are given and fig. 3 shows the histogram of all suppliers with their efficiency score.

Table 4. Average efficiency and weights of 18 suppliers in 30 runs

\begin{tabular}{|c|c|c|c|c|c|c|}
\hline \multirow{2}{*}{$\begin{array}{c}\text { Sup } \\
\text { plie } \\
\text { rs }\end{array}$} & \multicolumn{6}{|c|}{ Value of input and output weight } \\
\hline & $Z_{1}$ & $Z_{2}$ & $Z_{3}$ & $W_{l}$ & $W_{2}$ & Efficiency \\
\hline 1 & 0.5864615 & 0.0021643 & 0.0077285 & 0.0093171 & 0.00422648 & 0.885125 \\
\hline 2 & 1 & 0 & 0 & 0.0096163 & $0.08283 \mathrm{e}-017$ & 0.942402 \\
\hline 3 & 0.0668079 & 0.0088852 & 0 & 0.0070293 & $0.33556 \mathrm{e}-01$ & 0.0843525 \\
\hline 4 & 0.0790911 & 0.010519 & 0 & 0.0083216 & 0.00248747 & 0.832165 \\
\hline 5 & 0.107364 & 0.0142795 & 0 & 0.0112962 & 0.0219116 & 0.734253 \\
\hline 6 & 0.0657469 & 0.0085730 & 0.0003544 & 0.0073778 & 0.00230969 & 0.811567 \\
\hline 7 & 0.32575 & 0.0020776 & 0.0074189 & 0.0089439 & $0.58488 \mathrm{e}-01$ & 0.822839 \\
\hline 8 & 0.0683372 & 0.0090886 & $0.89 \mathrm{E}-20$ & 0.0071902 & 0.0327347 & 0.524889 \\
\hline 9 & 1 & 0 & 0 & 0.0096163 & 0.0498655 & 0.721226 \\
\hline 10 & 0.0702566 & 0.0091611 & 0.0003788 & 0.0078839 & 0.0305688 & 0.638597 \\
\hline 11 & 0.0321097 & 0.0136241 & 0.0008513 & 0.0089303 & 0.0031707 & 1 \\
\hline 12 & 0.0984692 & 0.0092357 & 0.0015945 & 0.0102223 & $0.29418 \mathrm{e}-018$ & 0.8689 \\
\hline 13 & 0.0863947 & 0.0114904 & 0 & 0.0090900 & 0.0363442 & 0.636303 \\
\hline 14 & 0.0208733 & 0.0068106 & 0.0043416 & 0.0090108 & 0.0315172 & 1 \\
\hline 15 & 0.0747521 & 0.0099419 & 0 & 0.0078651 & $0.14697 \mathrm{e}-017$ & 0.983144 \\
\hline 16 & 0.0632637 & 0.0082492 & 0.0003411 & 0.0070992 & 0.0280174 & 0.468551 \\
\hline 17 & 1 & 0 & 0 & 0.0096163 & 0.0625062 & 1 \\
\hline 18 & 0.0774918 & 0.0103063 & 0.66829 & 0.0081534 & $0.01723 e-014$ & 0.448437 \\
\hline
\end{tabular}

Table 5. Suppliers' efficiency

\begin{tabular}{|l|c|l|c|}
\hline Suppliers & Efficiency & Suppliers & Efficiency \\
\hline $\mathbf{1}$ & 0.885125 & $\mathbf{1 0}$ & 0.638597 \\
\hline $\mathbf{2}$ & 0.942402 & $\mathbf{1 1}$ & $\mathbf{1}$ \\
\hline $\mathbf{3}$ & 0.0843525 & $\mathbf{1 2}$ & 0.8689 \\
\hline $\mathbf{4}$ & 0.832165 & $\mathbf{1 3}$ & 0.636303 \\
\hline $\mathbf{5}$ & 0.734253 & $\mathbf{1 4}$ & $\mathbf{1}$ \\
\hline $\mathbf{6}$ & 0.811567 & $\mathbf{1 5}$ & 0.983144 \\
\hline $\mathbf{7}$ & 0.822839 & $\mathbf{1 6}$ & 0.468551 \\
\hline $\mathbf{8}$ & 0.524889 & $\mathbf{1 7}$ & $\mathbf{1}$ \\
\hline $\mathbf{9}$ & 0.721226 & $\mathbf{1 8}$ & 0.448437 \\
\hline
\end{tabular}




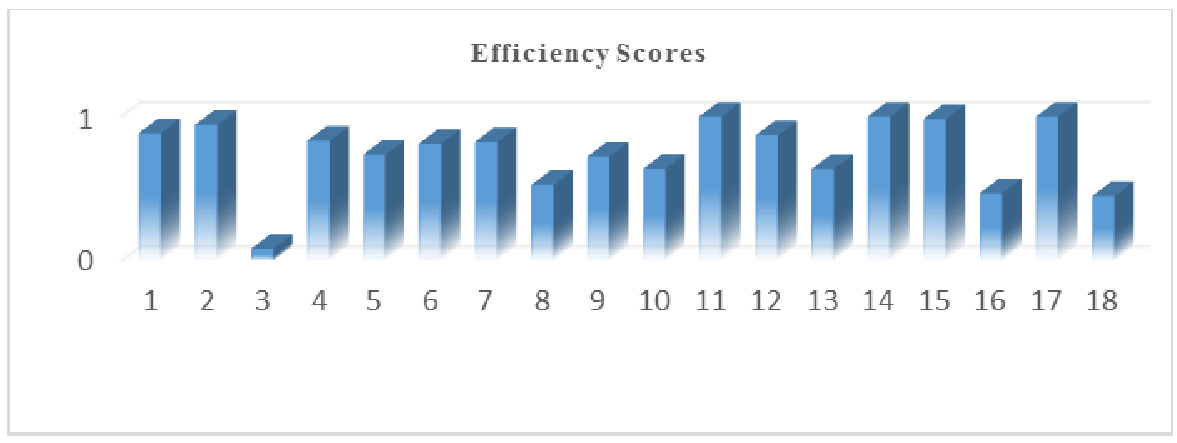

Fig. 3. Histogram of all suppliers with their efficiency score

\section{Conclusion and Summary}

SSS is a challenging task among thousands of potential suppliers. The present study shows DE algorithm as a tool for selecting the optimal sustainable suppliers. In this research work, we present a novel SSS approach for pulp and paper industry. The first step is to build a criterion set that comprising both Input as well as Output factors, which is appropriate for real world applications. We then present an approach to solve the multiple-criteria SSS problem with the application of DE, for DEA based mathematical model. By using this tactics, the business firms can acquire a desirable cluster of competent sustainable suppliers. In this study, the goal was the application of DE algorithm to the efficient SSS in the SCM.

The main motivation of this study was to gain an understanding of the mechanics of DE algorithm and to determine the accuracy of DE in generating the optimum solutions for the DEA based mathematical model, which is the underlying optimization problem for the aforementioned purchasing system. To our best information, this is the first time that the DE algorithm is applied to the SSS. This research article presents a DEA model for SSS practice in SCM. The key offerings of this research are précised as below: (1) SSS in SCM: to date, there are a small number of researches seeing sustainable concern in the supplier selection practice. (2) The selection criteria on the basis of sustainable concern are collected by means of the literature after that these are put in to the mathematical model for the SSS practice. (3) The present model can be carrying out for any quantity of suppliers and criteria's in the great size business firms. (4) In spite of the fact that many attempts have been made for the supplier selection, taking into consideration sustainable concern for this problem remains a demanding task. (5) Future research may explore the practice of the DE algorithm to find a solution to more difficult problem such as multi objective SSS.

\section{References}

1. Storn, R., Price, K.: Differential evolution-a simple and efficient adaptive scheme for global optimization over continuous spaces, Berkeley, CA, Tech. Rep. TR-95-012 (1995)

2. Plagianakos, V., Tasoulis, D., Vrahatis, M.: A Review of Major Application Areas of Differential Evolution. In: Chakraborty, U.K. (ed.) Advances in Differential Evolution. SCI, vol. 143, pp. 197-238. Springer, Berlin (2008) 
3. Wang, F., Jang, H.: Parameter estimation of a bio reaction model by hybrid differential evolution. In: Proceedings of IEEE Congress on Evolutionary Computation (CEC 2000), pp. 410-417 (2000)

4. Joshi, R., Sanderson, A.: Minimal representation multi sensor fusion using differential evolution. IEEE Trans. Syst. Man Cybern. Part A Syst. Hum. 29(1), 63-76 (1999)

5. Ilonen, J., Kamarainen, J., Lampine, J.: Differential evolution training algorithm for feedforward neural networks. Neural Process. Lett. 17(1), 93-105 (2003)

6. Ali, M., Siarry, P., Pant, M.: An efficient differential evolution based algorithm for solving multi-objective optimization. European Journal of Operational Research (2011)

7. Supply Chain Management in Pulp and Paper Industry, https: / /www. cirrelt.ca/DocumentsTravail/2006/DT-2006-AM-3.pdf (accessed on February 02, 2014)

8. Available and Emerging Technologies For Reducing Greenhouse Gas Emissions From The Pulp and Paper Manufacturing Industry, http: / / www . epa.gov/nsr/ghgdocs / pulpandpaper.pdf

9. Philpott, A., Everett, G.: Supply chain optimisation in the paper industry. Annals of Operations Research 108(1-4), 225-237 (2001)

10. Martel, A., M'Barek, W., D'Amours, S.: International factors in the design of multinational supply chains: the case of Canadian pulp and paper companies. Document de travail DT-2005-AM-3, Centor, Université Laval. 10 (2005)

11. Pulp and Paper Technology I Article, http: / / www . pulpandpapertechnology.com/articles/id/29 (accessed on February 02, 2014)

12. Agarwal, P., Sahai, M., Mishra, V., Bag, M., Singh, V.: A review of multi-criteria techniques for supplier evaluation and selection. International Journal of Industrial Engineering Computations 2 (2011), doi:10 5267/j ijiec 201106004

13. Weber, C.A., Current, J.R., Benton, W.C.: Vendor selection criteria and methods. European Journal of Operational Research 50(1), 2-18 (1991)

14. Degraeve, Z., Labro, E., Roodhooft, F.: An evaluation of vendor selection models from a total cost of ownership perspective. European Journal of Operational Research 125(1), 34 $58(1991)$

15. Boer, L., Labro, E., Morlacchi, P.: A review of methods supporting supplier selection. European Journal of Purchasing \& Supply Management 7(2), 75-89 (2000)

16. Holt, G.D.: Which Contractor Selection Methodology? International Journal of Project Management 16(3), 153-164 (1998)

17. Aamer, A.M., Sawhney, R.: Review of Suppliers Selection from a Production Perspective. In: Proc. IIE Conference, pp. 2135-2140 (2004)

18. Ho, W., Xu, X., Dey, P.K.: Multi-criteria decision making approaches for supplier evaluation and selection: A literature review. European Journal of Operational Research 202, 1624 (2010)

19. Tahriri, F., Osman, M.R., Ali, A., Yusuff, R.M.: A review of supplier selection methods in manufacturing industries. Suranaree Journal of Science and Technology 15(3), 201-208 (2008)

20. Cheraghi, S.H., Dadashzadeh, M., Subramanian, M.: Critical success factors for supplier selection: An update. Journal of Applied Business Research 20(2), 91-108 (2011)

21. Jauha, S.K., Pant, M.: Recent trends in supply chain management: A soft computing approach. In: Jagdish, C., Bansal, P., Singh, K., Deep, M., Pant, A. (eds.) Proceedings of Seventh International Conference on Bio-Inspired Computing: Theories and Applications (BIC-TA 2012). AISC, vol. 202, pp. 465-478. Springer, India (2013) 
22. Jauhar, S.K., Pant, M., Deep, A.: An Approach to Solve Multi-criteria Supplier Selection While Considering Environmental Aspects Using Differential Evolution. In: Panigrahi, B.K., Suganthan, P.N., Das, S., Dash, S.S. (eds.) SEMCCO 2013, Part I. LNCS, vol. 8297, pp. 199-208. Springer, Heidelberg (2013)

23. Jauhar, S.K., Pant, M.: Supplier selection in SCM: A decision making approach. In: Proceeding of OPTIMA 2012, University of Delhi, India, November 29-December 01 (2012)

24. Jauhar, S., Pant, M., Deep, A.: Differential Evolution for Supplier Selection Problem: A DEA Based Approach. In: Pant, M., Deep, K., Nagar, A., Bansal, J.C. (eds.) Third International Conference on Soft Computing for Problem Solving. AISC, vol. 258, pp. 343-353. Springer, India (2014)

25. Jayal, A.D., Badurdeen, F., Dillon Jr., O.W., Jawahir, I.S.: Sustainable manufacturing: Modeling and optimization challenges at the product, process and system levels. CIRP Journal of Manufacturing Science and Technology 2(3), 144-152 (2010)

26. Floridi, M., Pagni, S., Falorni, S., Luzzati, T.: An exercise in composite indicators construction: Assessing the sustainability of Italian regions. Ecological Economics 70(8), 1440-1447 (2011)

27. Luthe, T., Schuckert, M.: Socially Responsible Investing-Implications for Leveraging Sustainable Development. In: Trends and Issues in Global Tourism 2011, pp. 315-321. Springer, Heidelberg (2011)

28. Paoletti, M.G., Gomiero, T., Pimentel, D.: Introduction to the special issue: Towards a more sustainable agriculture. Critical Reviews in Plant Sciences 30(1-2), 2-5 (2011)

29. Büyüközkan, G., Çifçi, G.: A novel fuzzy multi-criteria decision framework for sustainable supplier selection with incomplete information. Computers in Industry 62(2), 164-174 (2011)

30. Shirouyehzad, H., Lotfi, F.H., Dabestani, R.: A data envelopment analysis approach based on the service quality concept for vendor selection. In: International Conference on Computers \& Industrial Engineering, CIE 2009, July 6-9, pp. 426-430 (2009), doi:10.1109/ICCIE.2009.5223823

31. LOCOG Guidelines on Carbon Emissions of Products and Services, http: / /www. Iondon2012.com/documents /

locog-publications / locog-guidelines-on-carbon-emissionsof-products-and-services.pdf

32. Dimitris, K.S., Lamprini, V.S., Yiannis, G.S.: Data envelopment analysis with nonlinear virtual inputs and outputs. European Journal of Operational Research 202, 604-613 (2009)

33. Ramanathan, R.: An Introduction to Data Envelopment Analysis: A Tool for Performance Measurement. Sage Publication Ltd., New Delhi (2003)

34. Wen, U.P., Chi, J.M.: Developing green supplier selection procedure: A DEA approach. In: 2010 IEEE 17th International Conference on Industrial Engineering and Engineering Management (IE\&EM), October 29-31, pp. 70-74 (2010), doi:10.1109/ICIEEM.2010.5646615

35. Vörösmarty, G., Dobos, I.: Supplier selection and evaluation decision considering environmental aspects.149. sz. Mőhelytanulmány, HU (October 2012) ISSN 1786-3031

36. Kumar, P., Mogha, S.K., Pant, M.: Differential Evolution for Data Envelopment Analysis. In: Deep, K., Nagar, A., Pant, M., Bansal, J.C. (eds.) Proceedings of the International Conference on SocProS 2011. AISC, vol. 130, pp. 311-319. Springer, Heidelberg (2012)

37. Srinivas, T.: Data envelopment analysis: models and extensions. Production/Operation Management Decision Line, 8-11 (2000)

38. Charnes, A., Cooper, W.W., Rhodes, E.: Measuring the efficiency of decision making units. European Journal of Operational Research 2(6), 429-444 (1978) 
39. Banker, R.D., Charnes, A., Cooper, W.W.: Some models for estimating technical and scale inefficiencies in data envelopment analysis. Management Science 30, 1078-1092 (1984)

40. Jouni, L.: A constraint handling approach for differential evolution algorithm. In: Proceeding of IEEE Congress on Evolutionary Computation (CEC 2002), pp. 1468-1473 (2002)

41. Coello, C.A.C.: Theoretical and numerical constraint handling techniques used with evolutionary algorithms: a survey of the state of the art. Computer Methods in Applied Mechanics and Engineering 191(11-12), 1245-1287 (2002)

42. Ray, T., Kang, T., Chye, S.K.: An evolutionary algorithm for constraint optimization. In: Whitley, D., Goldberg, D., Cantu-Paz, E., Spector, L., Parmee, I., Beyer, H.G. (eds.) Proceeding of the Genetic and Evolutionary Computation Conference (GECCO 2000), pp. 771-777 (2000) 